www.jmscr.igmpublication.org

Impact Factor (SJIF): 6.379

Index Copernicus Value: 79.54

ISSN (e)-2347-176x ISSN (p) 2455-0450

crossrefDOI: https://dx.doi.org/10.18535/jmscr/v6i9.04

Journal Of Medical Science And Clinical Research

\title{
Microbial Isolates from Wound Swabs: Antibiotic Resistance and Culture \& Sensitivity Patterns
}

\author{
Authors \\ Dr (Colonel) Gurmeet Singh Sarla*, Dr Vikas Dikshit \\ MH DEVLALI \\ *Corresponding Author \\ Dr (Colonel) Gurmeet Singh Sarla
}

\begin{abstract}
Wound infections continue to be problematic in clinical practice where empirical treatment of infections is routine. A retrospective study was carried out where records of wound swab samples from patients with different kinds of wounds receiving treatment at the department of Surgery in a peripheral hospital in Nasik were analysed. All none healing ulcers, burn wounds, diabetic foot ulcers, traumatic wounds, abscesses, surgical site infections were included in the study and wound swabs were obtained and culture and sensitivity tests were carried out. Out of 119 wound swabs sent for culture and sensitivity, 110 samples $(92.43 \%)$ revealed significant bacterial growth indicative of wound infection whereas 9 samples (7.56\%) showed no growth. Most patients from whom micro organisms grew were males (83.19\%) and the age group most commonly involved was 30-40 years (28.57\%).No sample grew more than one organism. Staph aureus was the most commonly isolated organism (66.36\%). The bacterial isolates exhibited a high degree of resistance to the antibiotics tested with most isolates showing resistance from $5.56 \%$ as in Chloramphenicol to $90.90 \%$ as seen in Imipenem. High resistance levels were found with Imipenem, Ampicillin, Augmentin, Cloxacillin, Carbenicillin, Ceftriaxone, Ceftazidime. The study showed moderate resistance to Ofloxacin, Ciprofloxacin, Azithromycin and Tiecoplanin. Low antibiotic resistance was seen with Chloramphenicol, Gentamycin, Amikacin, Clindamycin, Erythromycin, Levofloxacin, Linezolid, Polymyxin B, Piperacillin, Tobramycin, Vancomycin, Tetracyclin and Netilmycin.
\end{abstract}

\section{Introduction}

Wound infections continue to be problematic in clinical practice where empirical treatment of infections is routine. Most of the wound swabs revealed significant bacterial growth indicative of wound infection. No sample grew more than one organism. Staph aureus was the most commonly isolated organism. The bacterial isolates exhibited a high degree of resistance to the antibiotics tested with most isolates.

\section{Aim}

The aim of this study was to analyse wound swab samples from patients with different kinds of wounds being treated and study their culture and sensitivity reports and report the antibiotic resistance levels.

\section{Materials and Methods}

This was a retrospective study where records of wound swab samples obtained from Sep 2016 to 
Jul 2018 from patients with different kinds of wounds receiving treatment at the department of Surgery in a peripheral hospital in Nasik were analysed.

\section{Exclusion and inclusion criteria}

All non healing ulcers, burn wounds, diabetic foot ulcers, traumatic wounds, abscesses, surgical site infections were included in the study. Very ill patients and patients already on antibiotics were excluded.

\section{Sample collection}

Sample was collected by the operating / treating Surgeon in the Operating room under sterile conditions and after cleaning the wound with Normal Saline to prevent surface contamination. Commercially available cotton swabs were used and the sample was transported to the lab within one hour of collection to prevent drying of the swabs.

\section{Statistical Analysis}

Differences in antibiotic resistance between wound types and between sexes and age groups were analysed.

\section{Results}

\section{Prevalence of wound infection}

A total of 119 wound swabs were received by the lab of a peripheral hospital in Nasik, India sent from the operating room by department of General Surgery over a period of 2 years from Sep 2016 to Sep 2018 and were analysed.

99 patients $(83.19 \%)$ were males and 20 patients $(16.80 \%)$ were females from whom wound swabs were taken.

Figure1: Sex distribution of patients with significant bacterial growth:

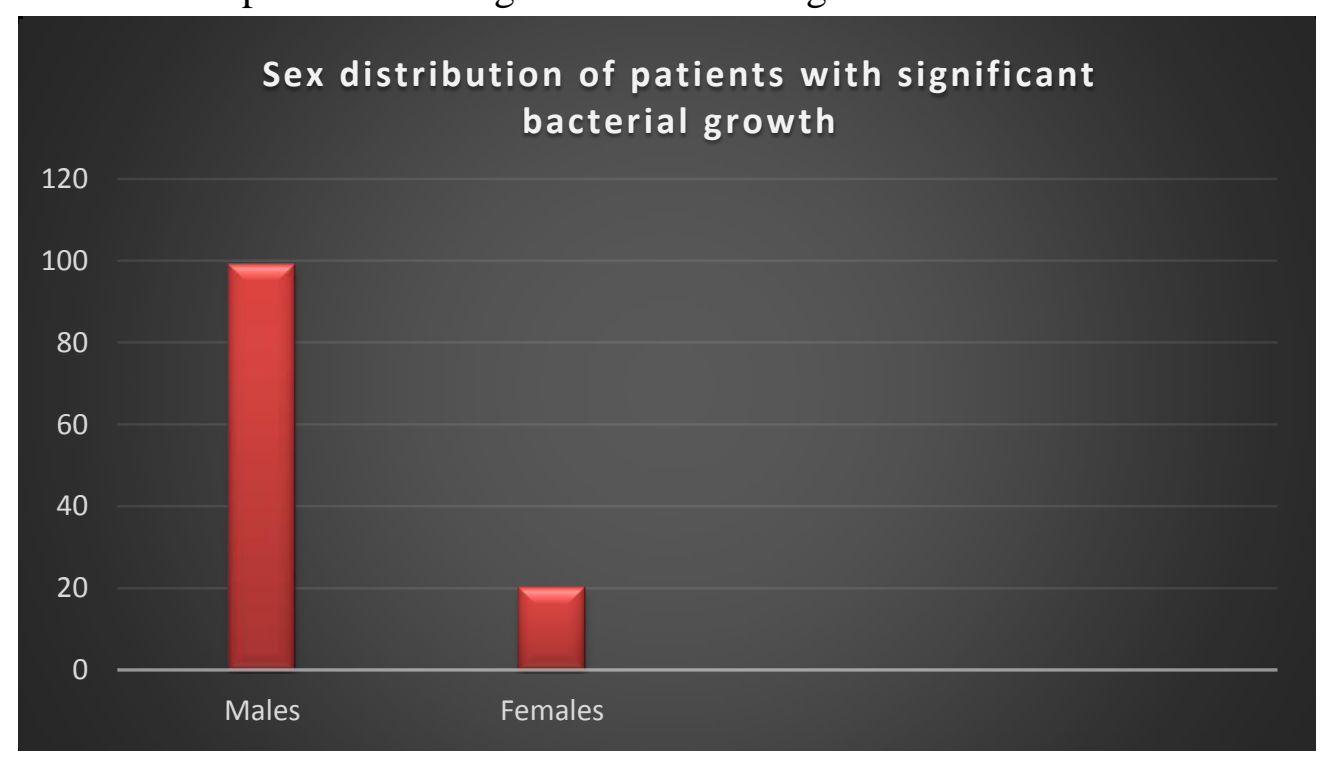

28 patients $(23.52 \%)$ were in the age group of $10-20$ years.

26 patients $(21.84 \%)$ were in the age group of $20-30$ years.

34 patients $(28.57 \%)$ were in the age group of $30-40$ years.

24 patients $(20.16 \%)$ were in the age group of $40-50$ years.

7 patients $(5.88 \%)$ were in the age group of 50-60 years. 


\section{JMSCR Vol||06||Issue||09||Page 25-33||September}

Figure 2: Age distribution of patients with significant bacterial growth

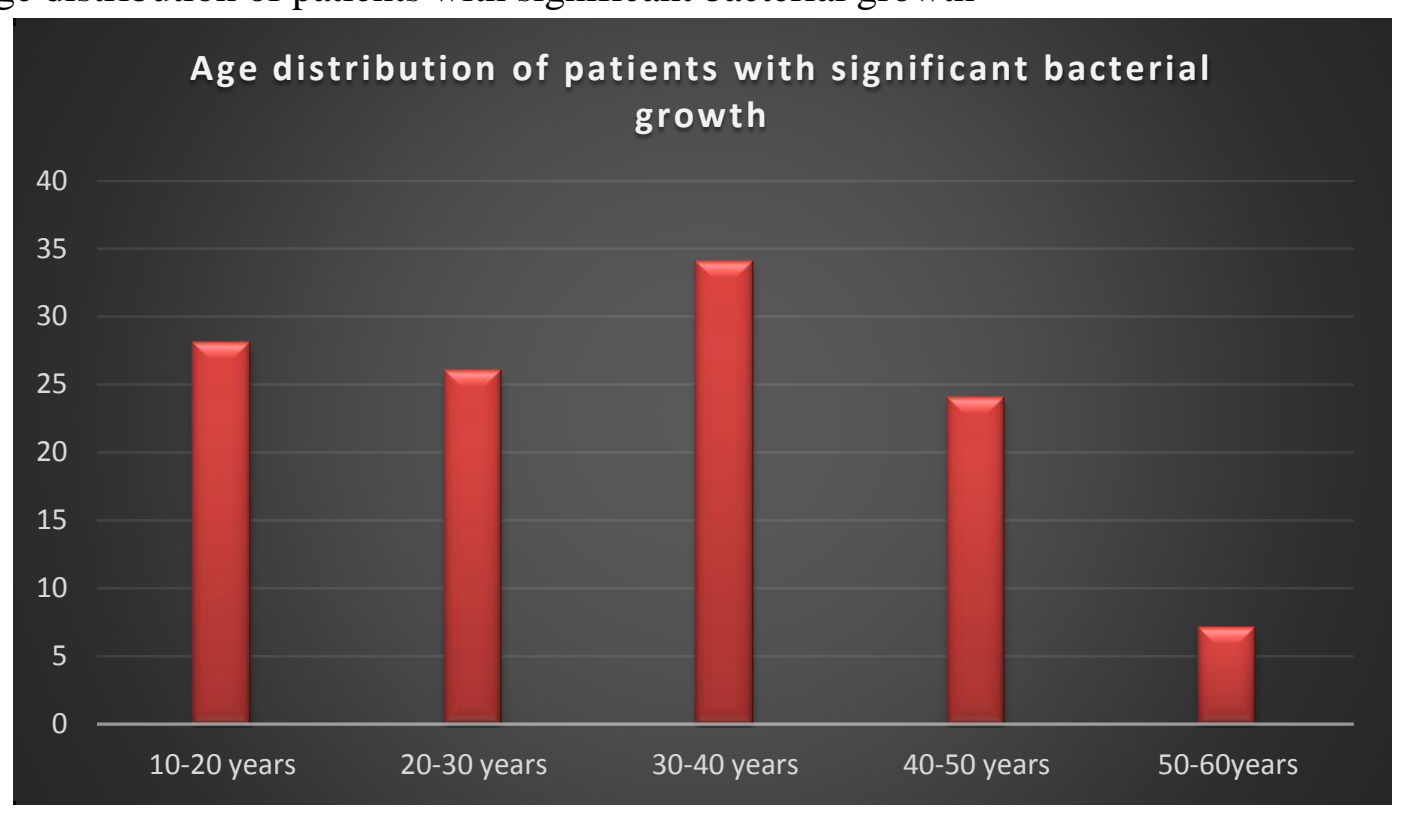

A total of 110 samples $(92.43 \%)$ revealed significant bacterial growth indicative of wound infection whereas 9 samples $(7.56 \%)$ showed no growth. No sample grew more than one organism.

\section{Micro organisms isolated}

73 wound swabs $(66.36 \%)$ grew Staph aureus, 5 (4.54\%) grew Proteus, $9 \quad((8.18 \%)$ grew Klebsiella, $17(15.45 \%)$ grew $\mathrm{E}$ Coli and 6 $(5.45 \%)$ grew Pseudomonas.

Figure 3: Micro- organisms isolated

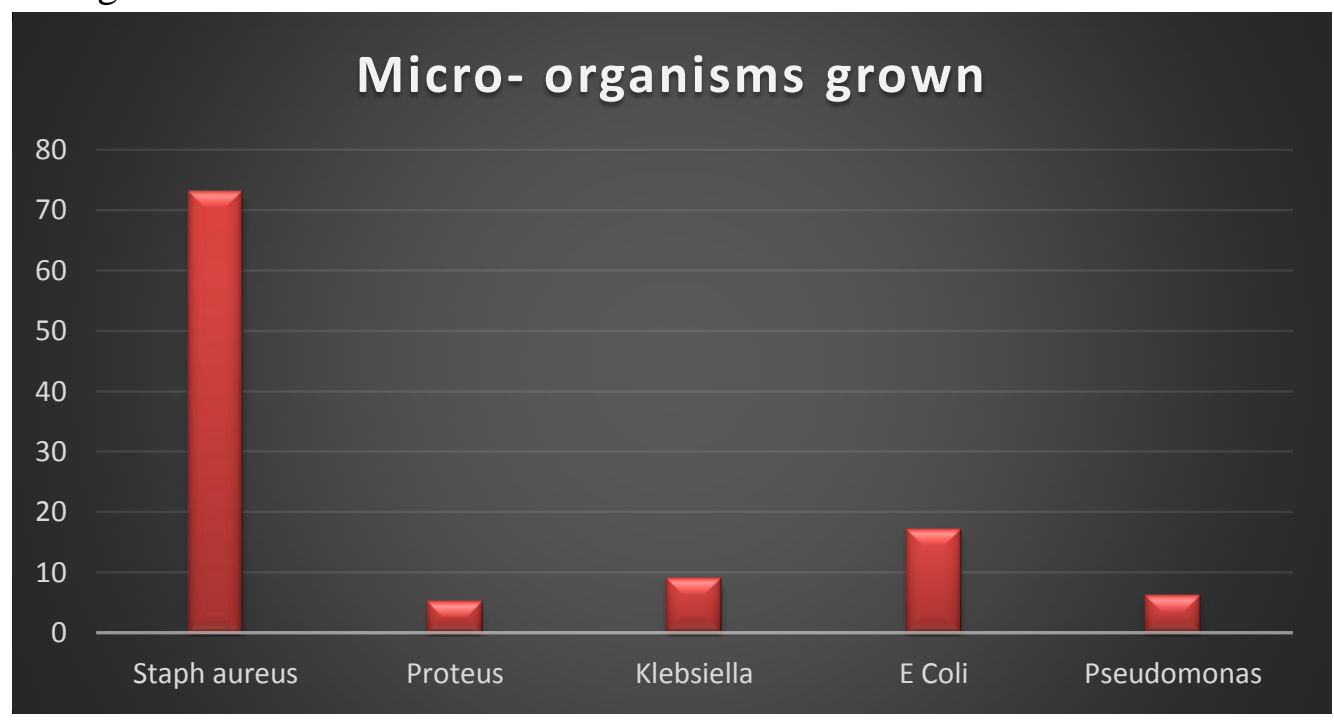

\section{Antibiotic resistance}

The bacterial isolates exhibited a high degree of resistance to the antibiotics tested with most isolates showing resistance from $5.56 \%$ as in Chloramphenicol to $90.90 \%$ as seen in Imipenem. High resistance levels were found with Imipenem, Ampicillin, Augmentin, Cloxacillin, Carbenicillin, Ceftriaxone, Ceftazidime. The study showed moderate resistance to Ofloxacin, Ciprofloxacin, Azithromycin and Tiecoplanin. Low antibiotic resistance were seen with Chloramphenicol, Gentamycin, Amikacin, Clindamycin, Erythromycin, Levofloxacin, Linezolid, Polymyxin B, Piperacillin, Tobramycin, Vancomycin, Tetracyclin and Netilmycin. 


\section{JMSCR Vol||06||Issue||09||Page 25-33||September}

Figure 4

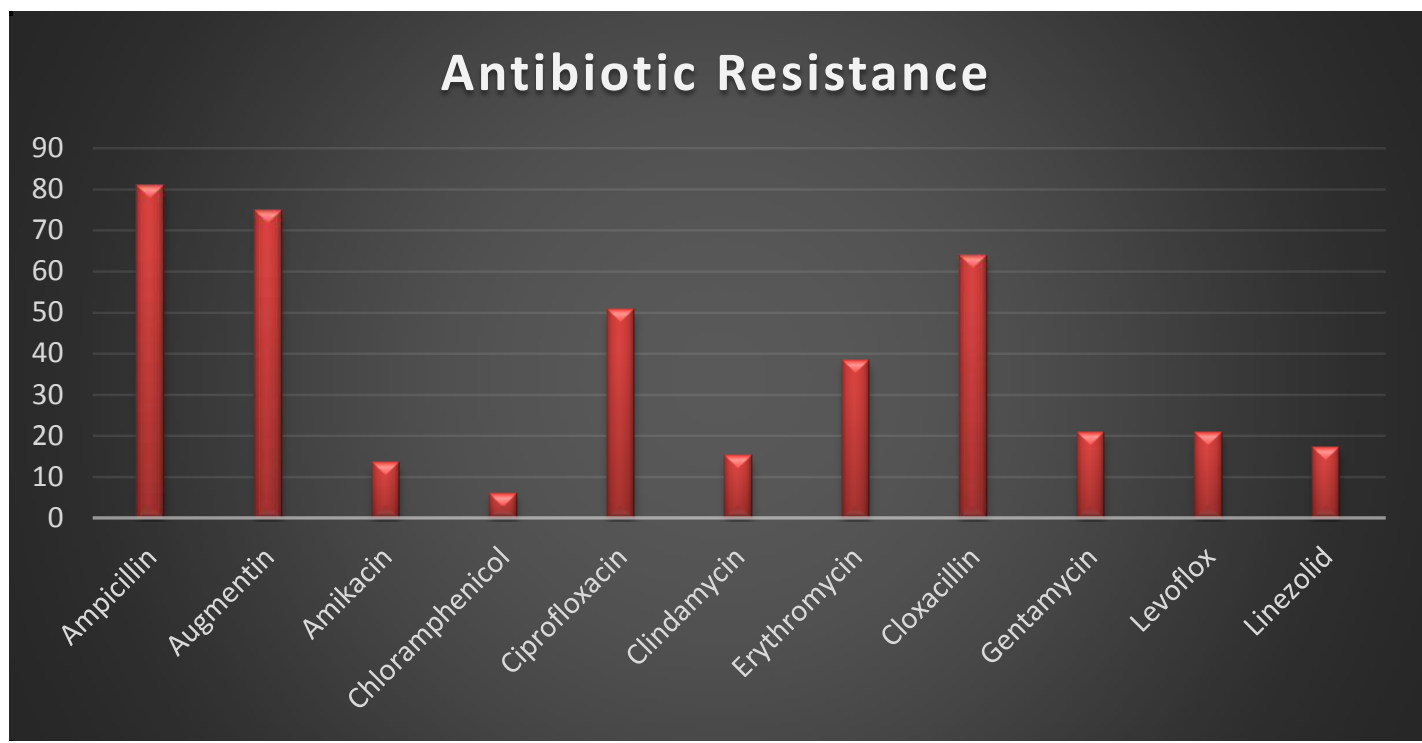

Figure 5

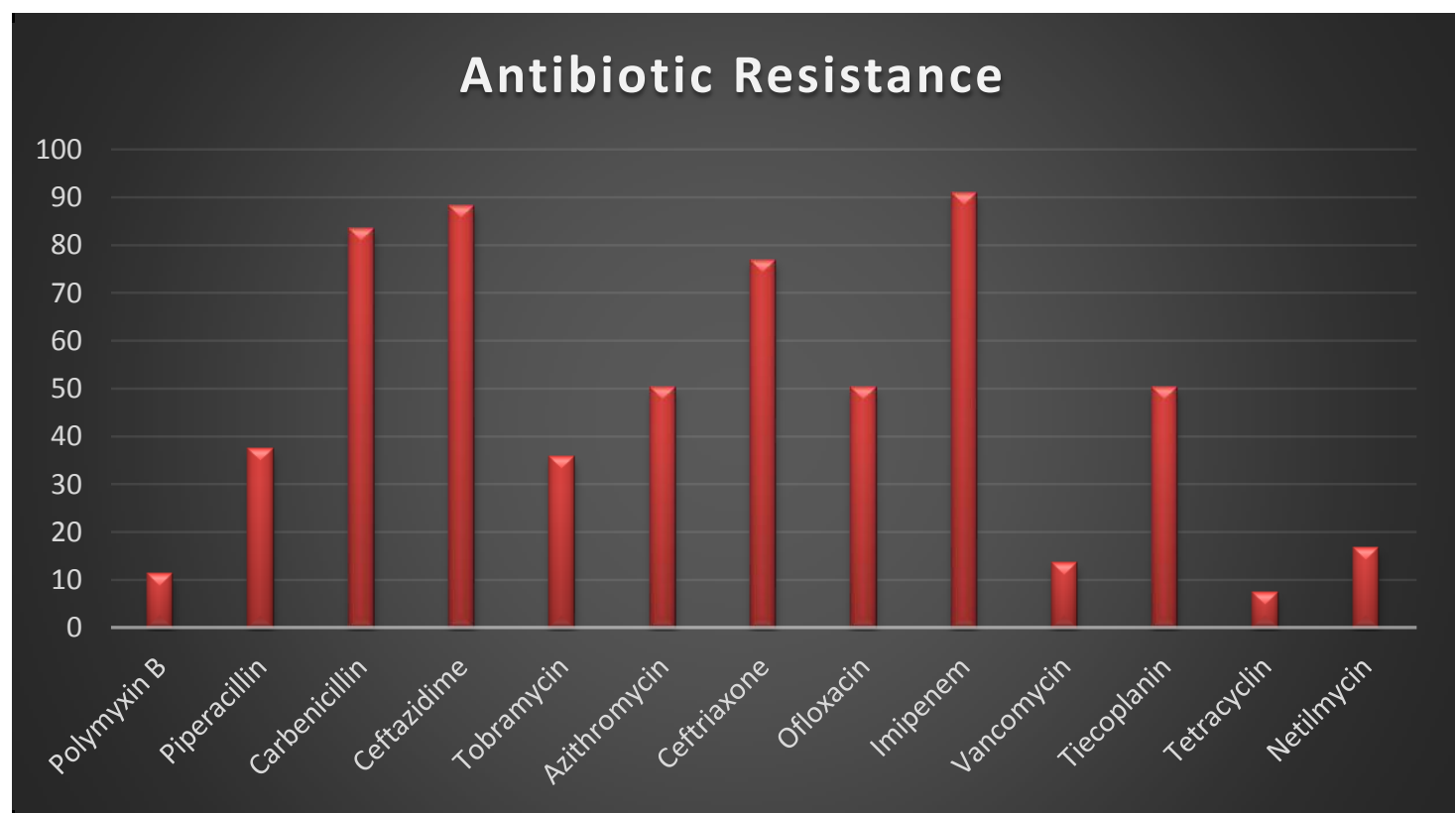

Degree of susceptibility of micro-organisms isolated to antibiotics expressed in percentage resistance:

Staph Aureus:

\section{Table 1:}

\begin{tabular}{|l|l|l|}
\hline Antibiotic & Sensitivity & Resistance \\
\hline Cotrimoxazole & $33.33 \%$ & $66.66 \%$ \\
\hline Erythromycin & $62.26 \%$ & $37.73 \%$ \\
\hline Gentamycin & $72.72 \%$ & $32.14 \%$ \\
\hline Levofloxacin & $84.21 \%$ & $15.78 \%$ \\
\hline Linezolid & $90.74 \%$ & $9.25 \%$ \\
\hline Ampicillin & $30.76 \%$ & $69.23 \%$ \\
\hline Augmentin & $19.60 \%$ & $80.39 \%$ \\
\hline Amikacin & $84.61 \%$ & $15.38 \%$ \\
\hline Ciprofloxacin & $41.17 \%$ & $58.82 \%$ \\
\hline Clindamycin & $87.93 \%$ & $12.06 \%$ \\
\hline
\end{tabular}




\section{JMSCR Vol||06||Issue||09||Page 25-33||September}

Figure 6

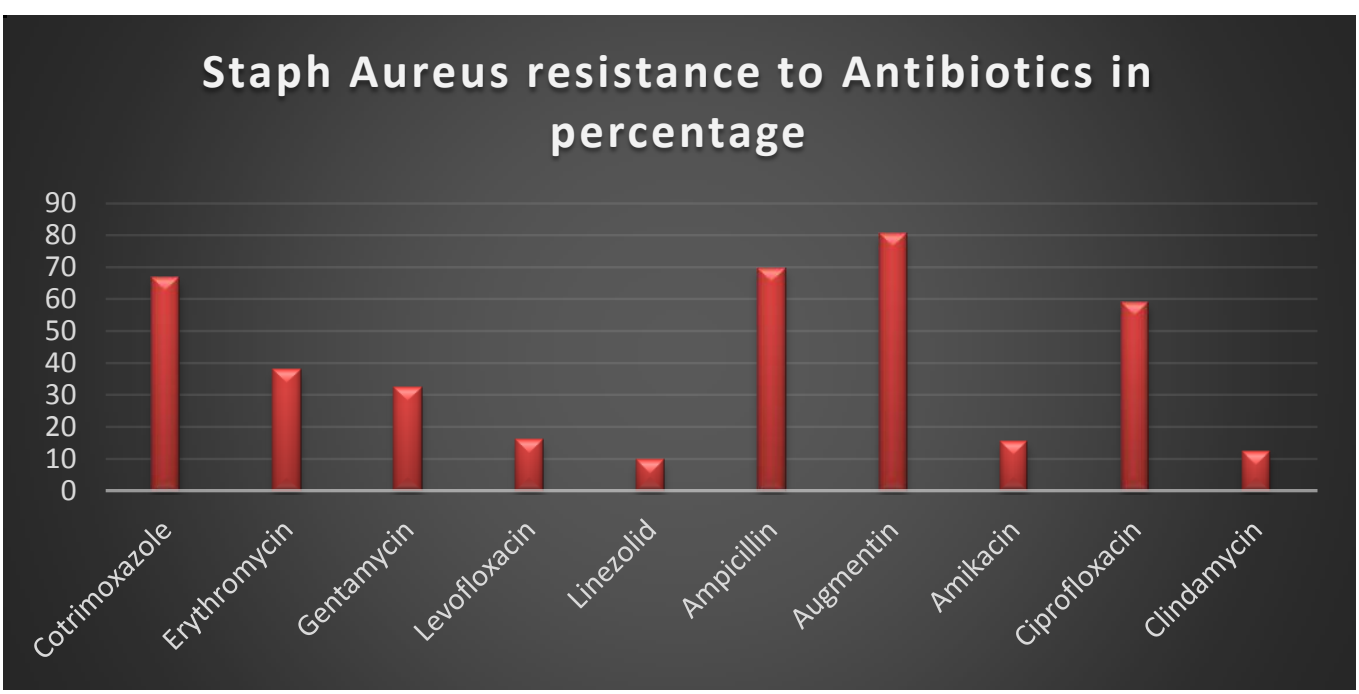

\section{Pseudomonas}

\section{Table 2}

\begin{tabular}{|l|c|c|}
\hline Antibiotic & Sensitivity & Resistance \\
\hline Amikacin & $85.71 \%$ & $14.28 \%$ \\
\hline Ciprofloxacin & $75 \%$ & $25 \%$ \\
\hline Gentamycin & $85.71 \%$ & $14.28 \%$ \\
\hline Piperacillin & $57.14 \%$ & $42.85 \%$ \\
\hline Ceftazidime & $20 \%$ & $80 \%$ \\
\hline Tobramycin & $66.66 \%$ & $33.33 \%$ \\
\hline Ceftriaxone & $0 \%$ & $100 \%$ \\
\hline
\end{tabular}

Figure 7

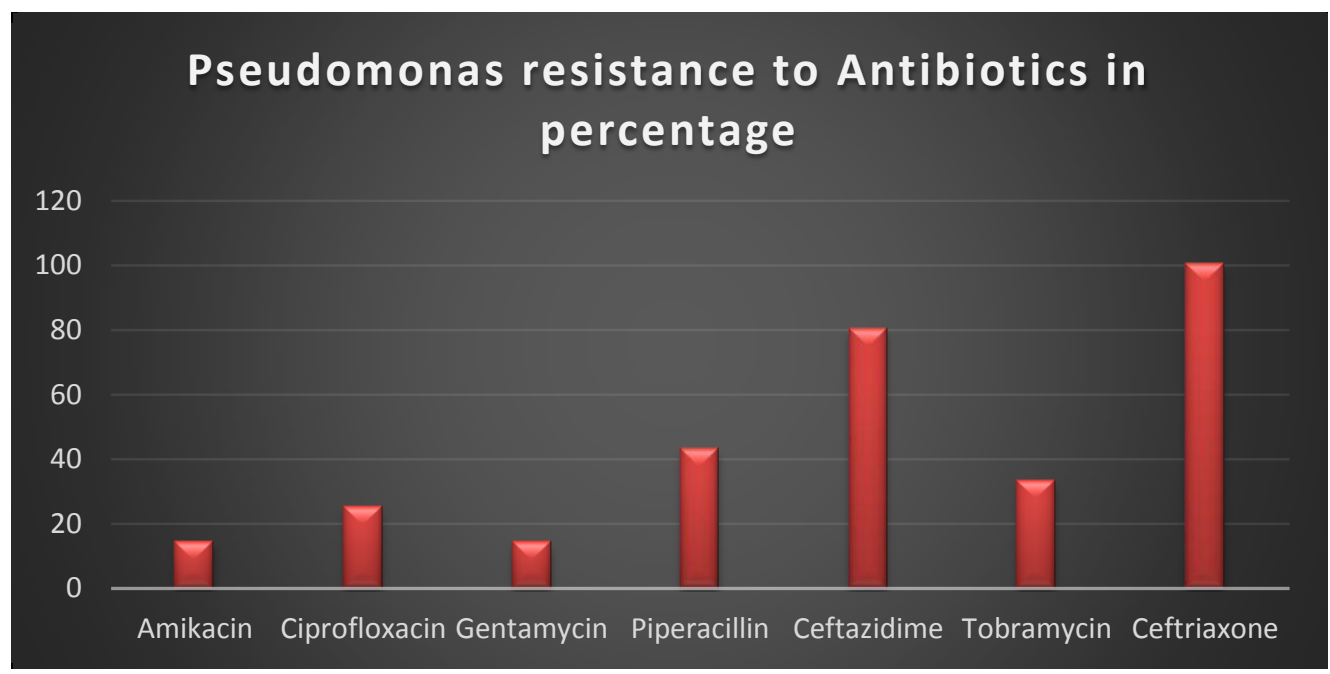

E Coli

Table 3

\begin{tabular}{|l|l|l|}
\hline Antibiotic & Sensitivity & Resistance \\
\hline Ampicillin & $22.22 \%$ & $77.77 \%$ \\
\hline Augmentin & $16.66 \%$ & $83.33 \%$ \\
\hline Amikacin & $85.71 \%$ & $14.28 \%$ \\
\hline Ciprofloxacin & $53.84 \%$ & $46.15 \%$ \\
\hline Gentamycin & $87.5 \%$ & $12.5 \%$ \\
\hline Netilmycin & $100 \%$ & $0 \%$ \\
\hline Tobramycin & $66.66 \%$ & $33.33 \%$ \\
\hline Cotrimoxazole & $14.28 \%$ & $85.71 \%$ \\
\hline
\end{tabular}




\section{JMSCR Vol||06||Issue||09||Page 25-33||September}

Figure 8

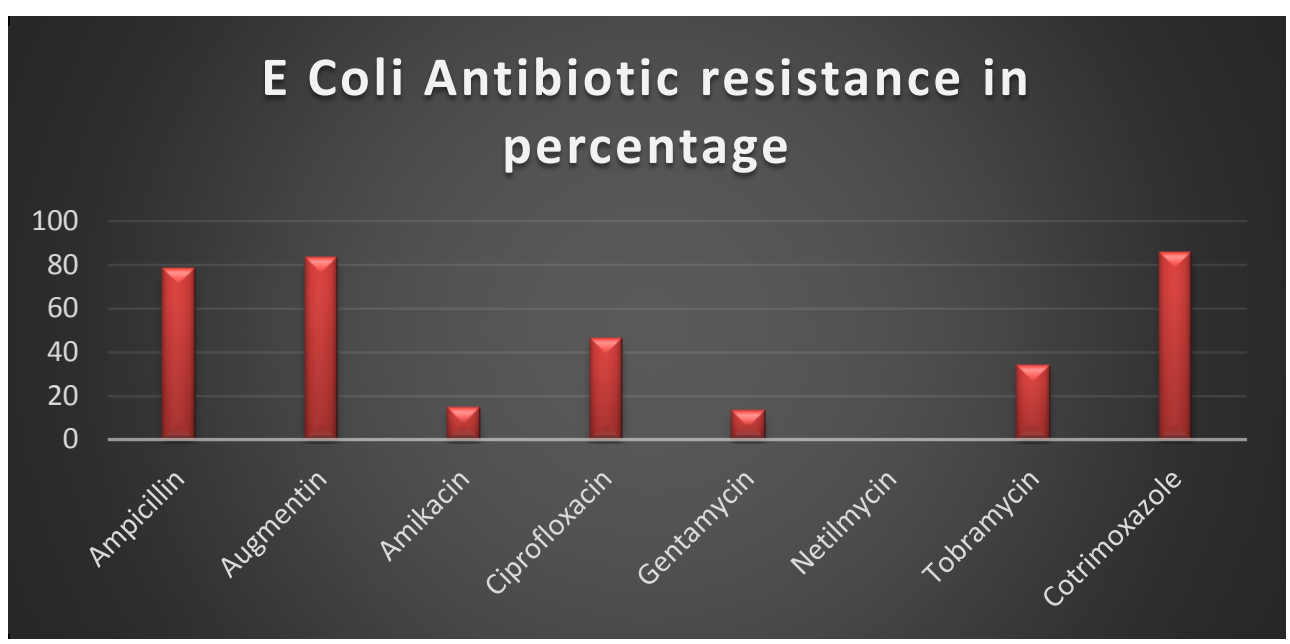

\section{Proteus}

Table 4

\begin{tabular}{|l|c|c|}
\hline Antibiotic & Sensitivity & Resistance \\
\hline Ampicillin & $25 \%$ & $75 \%$ \\
\hline Augmentin & $0 \%$ & $100 \%$ \\
\hline Amikacin & $87.5 \%$ & $12.5 \%$ \\
\hline Ciprofloxacin & $100 \%$ & $0 \%$ \\
\hline Gentamycin & $80 \%$ & $20 \%$ \\
\hline Cotrimoxazole & $40 \%$ & $60 \%$ \\
\hline
\end{tabular}

Figure 9

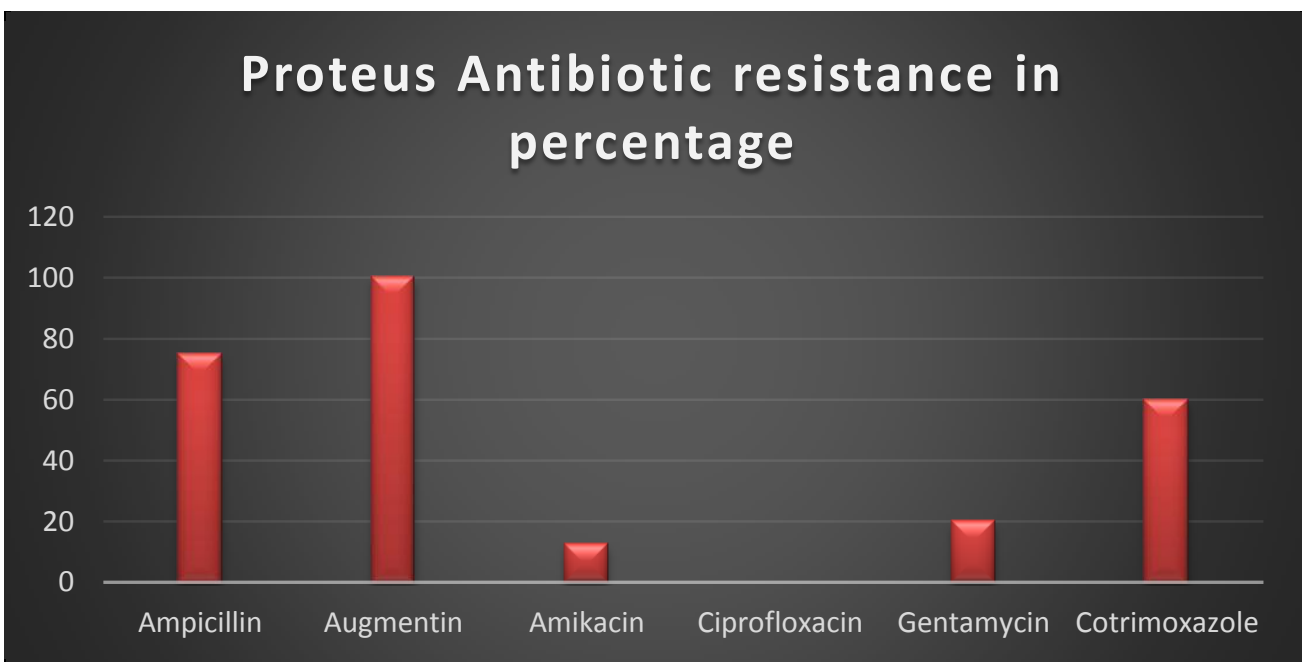

\section{Results}

A total of 110 samples $(92.43 \%)$ revealed significant bacterial growth indicative of wound infection whereas 9 samples $(7.56 \%)$ showed no growth.

99 patients $(83.19 \%)$ were males and 20 patients $(16.80 \%)$ were females from whom wound swabs were taken.

Most patients were in the age group of 30-40 years i.e.34 patients $(28.57 \%)$ whereas the least number of patients i.e.7 patients $(5.88 \%)$ were in the age group of 50-60 years.

No sample grew more than one organism.

73 wound swabs $(66.36 \%)$ grew Staph aureus, 5 $(4.54 \%)$ grew Proteus, 9 ((8.18\%) grew Klebsiella, 17 (15.45\%) grew E Coli and 6 (5.45\%) grew Pseudomonas. So to infer Staph aureus grew the most and Proteus grew the least. The bacterial isolates exhibited a high degree of resistance to the antibiotics tested with most 
isolates showing resistance from $5.56 \%$ as in Chloramphenicol to $90.90 \%$ as seen in Imipenem. High resistance levels were found with Imipenem, Ampicillin, Augmentin, Cloxacillin, Carbenicillin, Ceftriaxone, Ceftazidime.

The study showed moderate resistance to Ofloxacin, Ciprofloxacin, Azithromycin and Tiecoplanin.

Low antibiotic resistance were seen with Chloramphenicol, Gentamycin, Amikacin, Clindamycin, Erythromycin, Levofloxacin, Linezolid, Polymyxin B, Piperacillin, Tobramycin, Vancomycin, Tetracyclin and Netilmycin.

Staph aureus was found to be most sensitive to Linezolid (90.74\%) and most resistant to Augmentin (80.39\%).

Pseudomonas was found to be most sensitive to Amikacin (85.71\%) and most resistant to Ceftriaxone (100\%).

E Coli was found to be most sensitive to Netilmycin (100\%) and most resistant to Cotrimoxazole (85.71\%).

Proteus was found to be most sensitive to Ciprofloxacin (100\%) and most resistant to Augmentin (100\%).

\section{Discussion}

Bacterial contamination of wounds is a serious problem in hospitals, specially in surgical practice where the site of a sterile operation can become contaminated and subsequently infected ${ }^{1}$.

Risk factors for increased risk of wound infection $^{2}$ :

\section{- Malnutrition}

- Metabolic diseases: Diabetes, Uraemia, Jaundice

- Immunosuppression: Cancer, AIDS, steroids, chemotherapy, radiotherapy

- Colonisation and translocation in GIT

- Poor perfusion ( Systemic shock, Local ischemia)

- Foreign body/material

- Poor surgical technique (dead space, haematoma)
A wound is a breakdown in protective function of skin, the loss of continuity of epithelium with or without loss of underlying connective tissue ${ }^{3}$. Infection is believed to occur when virulence factors expressed by one or more micro-organisms in a wound out- compete the host natural immune system $^{4}$. Wound infection is important because it can delay healing and can cause wound breakdown ${ }^{5}$.

If cultures are negative, empirical antibiotic therapy should usually be stopped after no more than 48-72 hours ${ }^{6}$. Unnecessary antibiotic therapy increases risk of multi drug resistance infection, so prolonged therapy with negative cultures is usually unjustifiable. The high degree of resistance may be attributed to the widespread abuse of antibiotics, practicing self medication, indiscriminate use of antibiotics as oral prophylaxis, lack of lab services and guidelines/ protocols regarding the selection of antibiotics ${ }^{7}$. Neu said "Bacteria are cleverer than men" as they have capacity to adapt in every environmental niche on the planet and now adjusting to a world laced with antibiotics ${ }^{11}$. The morbidity of antibiotic therapy includes allergic reactions, development of nosocomial super infections (fungal, enterococcal and $\mathrm{C}$ difficile related infections), organ toxicity, reduced yield from subsequent cultures and Vitamin $\mathrm{K}$ deficiency with coagulopathy or accentuation of warfarin effects ${ }^{6}$.

The high proportion of $S$. aureus as evident in this study might be because of endogenous source of infection or contamination from the environment such as contamination of surgical instruments with the disruption of natural skin barrier as these bacteria are a common bacterium on surfaces, easily finds their way into wounds ${ }^{8}$. The common bacterial pathogens responsible for wound infections are Staphylococcus aureus, Pseudomonas aeruginosa, and bacteria belonging to family Enterobacteriaceae ${ }^{9}$. Since the emergence of methicillin-resistant Staphylococcus

aureus (MRSA) in 1960, there have been reports of increasing rate of infection by MRSA and this 
superbug has established itself as the common cause of nosocomial as well as community acquired infections ${ }^{10}$.

The increased prevalence of drug resistance mainly methicillin resistance among the strains of $S$. aureus has impelled the usage of macrolidelincosamide-streptogramin $\mathrm{B}\left(\mathrm{MLS}_{\mathrm{B}}\right)$ antibiotics mainly clindamycin for the treatment of the infections caused by Staph aureus ${ }^{12}$. Clindamycin is considered as one of the drugs of choice for treatment of the infection caused by MRSA ${ }^{13}$.

Antibacterial agents for empirical use ${ }^{6}$ :

- Antipseudomonal: Piperacillin - Tazobactum, Cefipime, Ceftazidime, Imipenem-cilastatin

- Gram positive: Vancomycin, Linezolid

- Gram negative: Third generation Cephalosporin, Polymyxin B

- Anti- anaerobic: Metronidazole, Carbepenems

- Broad spectrum : Piperacillin- Tazobactum, Carbepenems, Fluoroquinolones, Tigecycline

- Anti MRSA: Linezolid, Vancomycin, Tigecycline, Minocycline

Treatment guidelines must be continuously revised as susceptibility to antibiotic drugs is constantly threatened due to an empirical approach to treatment and high self-medication of humans and animals without a medical prescription ${ }^{14}$. Enforcing a strict adherence policy in the healthcare sector to reduce the development and spread of drug-resistant bacterial strains goes hand in hand with nationwide antimicrobial surveillance. Routine clinical diagnostic laboratories can contribute to the national surveillance network by sharing routine antibiograms from clinical samples ${ }^{15}$.

\section{Conclusion}

Severe antimicrobial resistance in wound infections was observed among patients treated for wound infections by department of Surgery in a peripheral hospital in Nasik. There is a need for serious and urgent intervention to stem the spread and further evolution of this antibiotic resistance. A rigorous infection control policy along with rational use of antibiotics will go a long way in fighting against antibiotic resistance. Since a high proportion of samples had positive cultures, infection control is recommended as a strategy to minimise spread of resistant organisms. It is recommended that Linezolid, Amikacin, Ciprofloxacin and Netilmycin be used in preference to Ampicillin, Amoxycillin and Ceftriaxone for treatment of septic wounds. Finally, there is need to develop national surveillance of antibiotic- resistant organisms.

\section{References}

1. Odelowo E, Onile B. Peri-operative infections in Nigerians: A seven years prospective study. East Afr Med J 1990; 67(3): 172-181

2. RCG Russell, Norman S Williams, Christopher JK Bulstrode. Bailey \& Love's Short Practice of Surgery: 88

3. Leaper DJ, Harding KG. Wounds: Biology and Management. Oxford, England: Oxford University Press; 1998

4. Bowler P, Duerden I, Armstrong D. Wound microbiology and associated approaches to wound management. Clin Microbiol Rev 2001; 14(2): 244-269

5. Alexander FM. Wound Infection: Nursing Practice Hospital and Home, the Adult. New York: Churchill Livingstone; 1994

6. Beauchamp, Evers, Mattox. Sabiston Textbook of Surgery:255-256

7. Hart CA, Kariuki S. Antimicrobial resistance in developing countries. BMJ. 1998;317:647-50.

8. Mama M, Abdissa A, Sewunet T. Antimicrobial susceptibility pattern of bacterial isolates from wound infection and their sensitivity to alternative topical agents at Jimma University specialized Hospital, South-West Ethiopia. Ann Clin Microbiol Antimicrob. 2014;13:14.

9. Mordi R. M., Momoh M. I. Incidence of Proteus species in wound infections and their sensitivity pattern in the University of 
Benin Teaching Hospital. African Journal of Biotechnology. 2009;8(5):725-730.

10. Khanal L. K., Jha B. K. Prevalence of methicillin resistant Staphylococcus aureus (MRSA) among skin infection cases at a hospital in Chitwan, Nepal. Nepal Medical College Journal. 2010;12(4):224-228.

11. Storoe W, Haug RH, Lillich TT. The changing face of odontogenic infections. J Oral Maxillofac Surg. 2001;59:739-48.

12. Deotale V, Mendiratta DK, Raut U, Narang P. Inducible clindamycin resistance in Staphylococcus aureus isolated from clinical samples. Indian J Med Microbiol. 2010;28:124-126.

13. Ansari S, Nepal HP, Gautam R, Rayamajhi N, Shrestha S, Upadhyay G, et al. Threat of drug resistant Staphylococcus aureus to health in Nepal. BMC Infect Dis. 2014; 14:157.

14. Zenebe T, Kannan S, Yilma D, Beyene G. Invasive bacterial pathogens and their antibiotic susceptibility patterns in Jimma Specialized Hospital, Jimma, Southwest Ethiopia. Ethiop J Health Sci. 2011;21:18.

15. O'Brien TF, Stelling J. Integrated multilevel surveillance of the world's infecting microbes and their resistance to antimicrobial agents. Clin Microbiol Rev. 2011;24:281-295. 